\title{
Non-publication and delayed publication of randomized trials on vaccines: survey
}

\author{
(C) $(1) \Theta$ OPEN ACCESS
}

\author{
Lamberto Manzoli associate professor ${ }^{12}$, Maria Elena Flacco resident physician ${ }^{13}$, Maddalena \\ D'Addario resident physician ${ }^{4}$, Lorenzo Capasso PhD student ${ }^{12}$, Corrado De Vito assistant \\ professor $^{6}$, Carolina Marzuillo assistant professor ${ }^{6}$, Paolo Villari professor ${ }^{6}$, John P A loannidis \\ professor $^{78}$
}

${ }^{1}$ Department of Medicine and Aging Sciences, University of Chieti, Via dei Vestini 566013 Chieti, Italy; ${ }^{2} \mathrm{CeSI}$ Biotech, Via Colle dell'Ara, Chieti, Italy; ${ }^{3}$ Local Health Unit of Pescara, Italy; ${ }^{4}$ Division of Clinical Epidemiology and Biostatistics, Institute of Social and Preventive Medicine, University of Bern, Switzerland; ${ }^{5}$ Division of International and Environmental Health, Institute of Social and Preventive Medicine, University of Bern, Switzerland; ${ }^{6}$ Department of Public Health and Infectious Diseases, Sapienza University of Rome, Italy; ${ }^{7}$ Stanford Prevention Research Center, Department of Medicine, Stanford University School of Medicine, Stanford, CA, USA; ${ }^{8}$ Department of Health Research and Policy, Stanford University School of Medicine, Stanford, CA, USA

\begin{abstract}
Objective To evaluate the extent of non-publication or delayed publication of registered randomized trials on vaccines, and to investigate potential determinants of delay to publication.

Design Survey.

Data sources Trials registry websites, Scopus, PubMed, Google.

Study selection Randomized controlled trials evaluating the safety or the efficacy or immunogenicity of human papillomavirus (HPV), pandemic A/H1N1 2009 influenza, and meningococcal, pneumococcal, and rotavirus vaccines that were registered in ClinicalTrials.gov, Current Controlled Trials, WHO International Clinical Trials Registry Platform, Clinical Study Register, or Indian, Australian-New Zealand, and Chinese trial registries in 2006-12. Electronic databases were searched up to February 2014 to identify published manuscripts containing trial results. These were reviewed and classified as positive, mixed, or negative. We also reviewed the results available in ClinicalTrials.gov.
\end{abstract}

Main outcome measures Publication status of trial results and time from completion to publication in peer reviewed journals.

Data synthesis Cox proportional hazards regression was used to evaluate potential predictors of publication delay.

Results We analysed 384 trials ( $85 \%$ sponsored by industry). Of 355 trials (404 758 participants) that were completed, $176(n=151379)$ had been published in peer reviewed journals. Another 42 trials (total sample 62765 ) remained unpublished but reported results in ClinicalTrials.gov. The proportion of trials published 12, 24, 36, and 48 months after completion was $12 \%, 29 \%, 53 \%$, and $73 \%$, respectively. Including results posted in ClinicalTrials.gov, 48 months after study completion results were available for $82 \%$ of the trials and $90 \%$ of the participants. Delay to publication between non-industry and industry sponsored trials did not differ, but non-industry sponsored trials were 4.42 -fold $(P=0.008)$ more likely to report negative or mixed findings. Negative results were reported by only $2 \%$ of the published trials.

Conclusions Most vaccine trials are published eventually or the results posted in ClinicalTrials.gov, but delays to publication of several years are common. Actions should focus on the timely dissemination of data from vaccine trials to the public.

\section{Introduction}

Randomized controlled trials are crucial in providing reliable and timely information about the effectiveness and safety of all healthcare interventions. ${ }^{1}$ In the case of emerging pandemics with modifying or even new infectious agents, such as the pandemic A/H1N1 2009 influenza virus, ${ }^{2}$ the availability of information on potential vaccines becomes even more time sensitive. ${ }^{3}$ While a time-lag in the dissemination of results may have adverse consequences for the practice of evidence based medicine and on public health for any disease, for epidemic diseases a delay in publication of relevant randomized controlled trials may distort the available evidence that is used for recommendations, allocation of resources, stockpiling of drugs and vaccines, and other public action. ${ }^{4}$ Even if trials do eventually get published years later, it may be too late, and the results may have less relevance because of the rapid changes in 
pathogens or vaccines. Even when pathogens or vaccines have not changed and late published trials are still relevant, the losses by having adopted suboptimal evidence over several years can still be substantial, given the wide use of many vaccines and the availability of many different formulations. It is important to have the best evidence and complete data from randomized trials to select the best vaccines and their best formulations for use in wide populations.

A growing body of evidence indicates that a relevant proportion of results from randomized trial remains unpublished, or is published after major delay. ${ }^{5-7}$ Although several studies have estimated the proportion of incomplete or selective reporting in various specialties, to our knowledge only two studies have focused on vaccines. ${ }^{8}{ }^{9} \mathrm{~A}$ first analysis evaluated the completeness of reporting of 70 randomized controlled trials of two vaccines based on the CONSORT 2010 checklist but did not assess delay to publication. ${ }^{9}$ In the other study, we evaluated the delay to publication of randomized trials on a single vaccine against $\mathrm{H} 1 \mathrm{~N} 1$ and found that most registered and completed trials were not published in the peer reviewed literature within two years from the onset of the pandemic. ${ }^{8}$

To examine whether similar problems of non-publication and delayed publication affect randomized controlled trials on a wide variety of vaccines we updated the previous survey on H1N1 trials and expanded the analysis to several other important vaccines, including human papillomavirus (HPV), rotavirus, pneumococcal, and meningococcal vaccines. We evaluated whether current concerns of non-publication should be extended to the vaccine literature. We also investigated the potential determinants, including sponsorship, of non-publication or delayed publication.

\section{Methods}

\section{Registered trials}

We initially searched for randomized controlled trials that evaluated the efficacy (including immunogenicity) or safety in healthy humans of selected vaccines (HPV, H1N1, meningococcal, pneumococcal, and rotavirus), had been registered in at least one of several clinical trial registries (US ClinicalTrials.gov, Current Controlled Trials, WHO International Clinical Trials Registry Platform, Clinical Study Register, and Indian, Australian-New Zealand, and Chinese Clinical Trial Registries) since 1 January 2006 and up to 31 December 2012. Two investigators independently carried out the search using the search terms: "vaccine OR vaccines OR vaccination OR immunization", and "pneumococcal" or "influenza" or "flu" or "meningococcal" or "meningococcus" or "rotavirus" or "HPV" or "papilloma virus" (all fields).

We did not include trials registered before 2006, because many of them were registered after the start of the study and some form of selection bias was to be expected (in some of these cases, trial registration even occurred retrospectively, after the decision to publish the results)..$^{10}$ Within the registries we excluded those trials that had been withdrawn before the start of enrollment, non-randomized trials, and duplicate registry entries. We considered trials registered after 1 January 2006 to be eligible for consideration in this analysis regardless of whether the registration date predated or antedated the reported start date of the trial. Multivariable analyses were repeated excluding all the trials that were registered after their start or only those registered after three months from the start date: given that all the main results were similar, the final analyses were based on all trials (details available from the authors).
We extracted information from the entries in the trial registry, including completion status, starting date, sample size, sponsors, and whether the results on the primary outcomes were available in the registry. For those trials that were reported as completed but the date of completion was missing $(n=11)$, we extracted the expected duration of the study (or, if not available, the expected duration of follow-up) and conservatively added one or two years (if the expected duration was shorter or longer than one year, respectively) to the expected duration. For the five trials that were indicated as not yet completed, even after the results had been published, we imputed as being completed three months before the publication date. One trial had some results posted on the registry website although the trial was reported as uncompleted and the expected completion date was December 2014: given that a primary publication was unlikely before the formal completion, we conservatively classified the trial as uncompleted.

Six trials did not report a start date: in such instances we used the date of first enrolment if available and, if missing, the date of inclusion in the registry. For sample size we used the number of participants listed in the section "planned or actual enrollment" of the enrollment field. ${ }^{10}$

\section{Published trials}

We searched PubMed, Scopus, and regular Google by trial registration code, principal investigator, country, keywords, and title for matching manuscripts and identified registered trials that had been published. The publication records on trial registries were reviewed when available. We classified those published reports that were found from just typing the registry identification code into PubMed or Scopus as "easily retrievable." We also searched whether the trial registry identification code was reported in published papers. When the identification code was not available in a published report, we matched the entry in the trial registry to the report only if the country, sample size (2 standard deviations), sponsor, vaccine type, and main outcomes were coincident, and dates compatible.

We considered a trial to be published if one or more of the main outcomes appeared in a peer reviewed journal, either online or in print. For trials published online ahead of print or those with results published more than once, we always extracted the earliest publication date. The last search update was on 1 February 2014, and we censored completion or publication dates of non-completed or non-published trials at that date.

Twenty four trials were still unpublished six or more years from the completion date. We defined such trials as "long since unpublished." To obtain additional information on these trials we emailed the contact person or institution listed in the registry, or if that was not possible we made a formal request through the institution's website form.

Two investigators evaluated and independently classified the published trial results as "positive" if the vaccine was efficacious or highly immunogenic, with no serious vaccine related adverse events, "mixed" if the results of primary outcomes were positive but those of other important outcomes were not, and "negative" if the vaccine showed an unequivocally low efficacy or immunogenicity or some serious vaccine related adverse events. We classified trials aimed at determining the optimum dose as positive if at least one of the doses or formulations showed high efficacy or immunogenicity and none reported serious adverse events. We did not use a single cut-off point for efficacy of safety outcomes to assign a negative or positive label, but we took into account the average literature values for each specific vaccine and outcome - that is, we considered a seroconversion 
rate of less than $50 \%$ for an influenza vaccine to be a negative value (further details are available from the authors). The inter-rater agreement between the two investigators was $87.6 \%$. Disagreements were solved through consensus, with the exception of four trials that required the opinion of a third investigator (LM). The results of four trials were published only pooled into a large integrated database. ${ }^{11}$ In descriptive analyses, we assigned the same judgment to all four trials.

\section{Statistical analyses}

We evaluated the time from starting a trial to its publication using Kaplan-Meier analysis considering all registered trials. We also evaluated with the log-rank test whether the time to publication was different for different sponsors, and then tested with Cox proportional hazards analysis whether there was any evidence that the risk of publication depended on the sponsor, sample size (log-transformed), and type of vaccine, adjusting for the date of starting. We performed both univariate and multivariable analyses, in which we included all these covariates. In secondary analyses we evaluated the time from starting a trial until its completion and the time from completion of a trial to its publication. We used the Schoenfeld test to check the proportional hazards assumption for all models and plotted Nelson-Aalen cumulative hazards estimates. We selected covariates a priori, but none of the other extracted trial or sample characteristics was found to be significantly associated with time to publication when added to the final models.

The analyses predicting time from start or completion of a trial to publication were repeated including among the published trials those that were not published in peer reviewed literature but had primary outcomes results reported in

ClinicalTrials.gov. ${ }^{12}$ For such analyses, the publication date was the date reported after the wording "results first received" for the unpublished trials; the earlier of either the publication date or the date that the results were made available on ClinicalTrials.gov for published trials.

Analyses were made in Stata 11.1 (Stata, College Station, TX, 2011). $P$ values are two tailed.

\section{Results}

\section{Trial characteristics and publication of trials}

Overall, 384 randomized controlled trials were registered in 2006-12 for vaccines against the pandemic A/H1N1 2009 influenza virus $(n=83), \operatorname{HPV}(n=60)$, rotavirus $(n=117)$, pneumococcus $(n=83)$, and meningococcus $(n=41$, table $1 \Downarrow)$. The figure $\downarrow$ shows the trial selection process. The two investigators agreed on $95 \%(n=363)$ of the 384 registered trials to be included, with the remaining discrepancies resolved through consensus.

Most of the registered trials $(n=355,92 \%)$ had been completed. After a median of 26.4 months from completion, 176 of the 355 completed trials had been published by February 2014 (50\%). Another $42(12 \%)$ of the 355 completed trials had primary outcome results available in ClinicalTrials.gov but were not published in a peer reviewed journal. When registered results were also included, the proportion of publications varied by vaccine and ranged from $43 \%$ (rotavirus; $n=15 / 35)$ to $64 \%$ (2009 $\mathrm{H} 1 \mathrm{~N} 1 ; \mathrm{n}=53 / 83$ ) and from $54 \%$ (meningococcal; $\mathrm{n}=58 / 108)$ to $72 \%(\mathrm{H} 1 \mathrm{~N} 1 ; \mathrm{n}=60 / 83)$. According to registry or publication data, the 355 completed trials include 404758 planned or actual participants. Of those, the 176 published trials included data on 151379 participants (37.4\%), and the 42 unpublished trials with results in ClinicalTrials.gov included data on 62765 participants
(15.5\%). After 12, 24, 36, and 48 months from completion, the proportion of published trials in Kaplan-Meier analyses was $12 \%(n=40 / 337), 29 \%(n=84 / 292), 53 \%(n=138 / 260)$, and $73 \%$ $(n=170 / 233)$, respectively (table 1$)$. Of the 63 trials that were not published after 48 months from completion, only six (10\%) were published later, but another $20(32 \%)$ had results posted in ClinicalTrials.gov. Including the trials with posted results in ClinicalTrials.gov, at 48 months after completion, results were estimated to be available from $82 \%$ of the trials $(n=210 / 255)$ and $90 \%$ of the participants ( $n=208$ 233/232 299).

Eighteen trials were published in generalist journals with a high impact factor-Lancet $(\mathrm{n}=6)$, JAMA $(\mathrm{n}=5)$, New England Journal of Medicine $(\mathrm{n}=5)$, and $B M J(\mathrm{n}=2)$, but most randomized controlled trials were published in specialized journals such as Vaccine (30\%; $\mathrm{n}=52 / 176)$ or the Pediatric Infectious Disease Journal (19\%; n=33/176). The median 2011 impact factor of the journals publishing papers was 3.78 (interquartile range 3.59-3.97, table 1). The trial registry identification code was reported in most of the papers $(90 \% ; n=159 / 176)$, and $75 \%$ of the published reports were easily retrievable through the trial registry number in Scopus or PubMed $(n=132 / 176)$.

Most trials had been registered before the start date $(81 \%$; $\mathrm{n}=311 / 384)$ or within three months of the start date $(13 \%$; $\mathrm{n}=49 / 384)$, had been registered in ClinicalTrials.gov $(90 \%$; $\mathrm{n}=347 / 384)$, were restricted to children (59\%; $n=227 / 384)$, had positive results when published $(90 \% ; \mathrm{n}=158 / 176)$, or had been supported by industry $(85 \% ; n=326 / 384$, table 1$)$.

\section{Analysis of trial sponsors}

Overall, the 58 non-industry sponsored trials enrolled only $9.7 \%$ of the total sample $(\mathrm{n}=59141 / 607076)$, and the proportion varied by vaccine, ranging from $2.1 \%$ (meningococcal; $\mathrm{n}=2444 / 118$ 813) to $39.2 \%$ (rotavirus; $\mathrm{n}=20290 / 51711$, table 1). Five companies funded $85 \%(n=276 / 326)$ of the industry sponsored trials: GlaxoSmithKline $(n=140)$, Novartis $(n=46)$, Pfizer/Wyeth ( $n=39)$, Sanofi-Aventis $(n=26)$, and Merck $(n=25)$. The publication rate of the completed trials largely varied by sponsor (table $2 \Downarrow$ ), ranging from $24 \%$ (six of the 25 randomized controlled trials sponsored by Merck) to $61 \%$ (GlaxoSmithKline; $\mathrm{n}=81 / 132$ ). Such differences were, however, not confirmed in multivariable analyses; it was $48 \%(n=22 / 46)$ for the studies funded by non-profit institutions versus 50\% $(n=154 / 309)$ for industry sponsored trials. Counting also the trials with results in ClinicalTrials.gov, the proportion of industry and non-industry sponsored trials that were published or had results available increased to 63\% $(n=194 / 309)$ and 52\% $(n=24 / 46)$, respectively (table 2). At 48 months after completion of the trials, these proportions became $82 \%(n=187 / 227)$ and $82 \%(n=23 / 28)$, respectively.

Trials not sponsored by industry were more likely to report negative or mixed results than industry sponsored trials (32\% $(7 / 22) v 7 \%$ (11/154), table 2). Such a difference remained significant when trials with results in ClinicalTrials.gov were also considered, and after adjusting for age-class, sample size, starting year, and vaccine type into a logistic model (odds ratio $4.42,95 \%$ confidence interval 1.45 to $13.5, \mathrm{P}=0.008$ ).

\section{Predictors of time from completion to publication, from start to completion, and from start to publication}

Both univariate and multivariable (table $3 \Downarrow$ ) analyses showed no statistically significant difference in the time from completion to publication between trials sponsored by for profit and not for profit institutions, either excluding (table 3 ) or including (see 
supplementary table 1 on bmj.com) the trials with results reported in ClinicalTrials.gov. Multivariable analysis also confirmed that trials of the H1N1 vaccine were published faster after completion than all other trials $(\mathrm{P}<0.001$; table 3 , supplementary table 1 on bmj.com).

Multivariable analysis showed that time to completion was significantly longer for larger trials, for trials on vaccines other than $\mathrm{H} 1 \mathrm{~N} 1$, and for trials sponsored by not for profit organizations (table 3). Time from start to publication was longer for trials of vaccines other than $\mathrm{H} 1 \mathrm{~N} 1$; no significant difference was found by sample size or sponsor type (table 3, see supplementary table 1 on bmj.com).

\section{Long since unpublished trials}

Supplementary table 2 on bmj.com shows the main characteristics of the 24 trials that remained unpublished after six years from completion. Most of those $(n=14 / 24)$ tested meningococcal vaccines, only one was sponsored by not for profit institutions, and only five reported results in

ClinicalTrials.gov. The 19 trials with no results at all included 11527 participants. Despite our attempts, none of the people or institutions that we tried to contact provided any additional information on these long since unpublished trials.

\section{Discussion}

Our empirical evaluation found that after a median of 26 months from completion, about half of the registered randomized trials on five vaccines had been published, and no information was available in the peer reviewed literature for almost two thirds of the entire sample of patients who had been randomized in these vaccine trials. Including the trials with results in ClinicalTrials.gov, the proportion of published trials increased to $61 \%$ (53\% of the randomized population sample). However, we observed that the results of many trials were posted or published with major delay. At four years after completion, data were available on peer reviewed journals for approximately $80 \%$ of the trial participants; or $90 \%$ when the results posted in ClinicalTrials.gov were also considered.

\section{Comparison with other studies}

Numerous articles on non-publication of trials across diverse specialties have been published in the past two decades. ${ }^{5} 810$ 13-20 The main characteristics of 31 studies have been summarized elsewhere, ${ }^{5}$ and 10 analyses that were not included are briefly described in supplementary table 3 on bmj.com. ${ }^{8}{ }^{13-20}$ The publication rate was lower than $60 \%$ in 30 out of 41 surveys, and a rate higher than $80 \%$ was reported only by three studies, which were based on selected samples of randomized controlled trials funded by the US National Institutes of Health, ${ }^{21}$ by the UK National Institute for Health Research Health Technology Assessment programme, ${ }^{22}$ or approved by John Hopkins institutional review boards. ${ }^{23}$ The vaccine trials that we evaluated were mainly sponsored by industry. As compared with the above literature, our estimate that results on approximately $80 \%$ of the participants can be published in journals four years after completion seems favorable. Previous studies were mostly performed before posting of the results in ClinicalTrials.gov started being adopted on a substantial scale. Our data show that posting of results in the registry can help improve the completeness of available evidence and offer some reassurance that the majority of trial results on vaccines do become available, but the wait may be long. However, timeliness and relevance of the evidence to current epidemic dynamics is of importance in this area of medicine, and old trials for some vaccines may often be of little value, even if published. ${ }^{24}$

Problems with timeliness and relevance are highlighted strongly by pandemics that come and go. In a previous analysis we found that two years after the emergence of the influenza $2009 \mathrm{H} 1 \mathrm{~N} 1$ pandemic less than $30 \%$ of the 73 registered randomized trials on the potential vaccines had been published, representing $38 \%$ of the randomized sample size. ${ }^{7}$ The present update showed a relevant improvement, as four years after trial completion the results of approximately $80 \%$ of the randomized participants had been published (90\% including results in ClinicalTrials.gov). However, data published more than four years (or even one year) after a pandemic (and vaccine distribution) are already of little or no value. For the other four vaccines that we assessed in our current study, problems of timeliness may not be as acute as for H1N1, but information can still be time sensitive, as it will affect guidelines, recommendations, and often annually renewed major decisions on the use of these vaccines for public health, as well as on the choice of the best, most effective, and most safe formulations, when multiple formulations of the same vaccine are available for use.

\section{Policy implications}

There are several ethical, legal, economic, and scientific reasons why clinical trial results should be published. ${ }^{5}$ Both the US Federal Policy for the Protection of Human Subjects and the Declaration of Helsinki ${ }^{25}$ acknowledge that investigators and sponsors have an ethical obligation to study participants to publish trial results. ${ }^{26}{ }^{27}$ Reporting results has been mandatory for many trials in the United States since 2007. ${ }^{28}$ Unpublished trials produce no scientific and social benefits, and their expenses, often large, are wasted. ${ }^{13}{ }^{14} 2930 \mathrm{We}$ suggest that the rationale for the publication of trial results should be extended to enforce not only publication but also timely publication or registration of these valuable results.

A randomized trials agenda where only fragments of the data are available may lead to a biased literature. ${ }^{56}$ When numerous intervention formulations are typically developed, it is not easy to extrapolate inferences from one formulation to another given the missing data. ${ }^{21}$ Also, there is a substantial literature in various specialties that trials with non-significant, less favorable, or even "negative" results are more likely to be unpublished or published late compared with significant trials or trials with results that are in line with investigators'

hypotheses. ${ }^{71416} 17192123{ }^{22-37}$ Furthermore, half of the 16 studies on the topic documented a lower likelihood of publication for the trials sponsored by industry. ${ }^{10} 23^{36-41}$ Vaccine trials are largely dominated by industry sponsorship. However, in our sample, we found no evidence of a longer time from completion to publication for such trials. In our sample, only four published trials reported negative findings (five including the trials with results in ClinicalTrials.gov), thus no meaningful analysis of the delay to publication according to trial findings can be attempted. However, we did observe a significantly lower proportion of negative and mixed findings in industry sponsored trials. Also, the extremely low proportion of negative results suggests that selective reporting biases favouring the publication of trials with positive results and positive analyses are possible, or even likely. When non-publication is considerable, published articles, as well as early reviews or meta-analyses that incorporate them, may be unreliable and overestimate the benefits of an intervention. ${ }^{72}$

It is certainly valuable that the results of the primary outcomes for 42 of the 179 unpublished trials $(23 \%)$ were posted in 
ClinicalTrials.gov (as well as 77 of the 176 published trials). Posting results on registry websites does not negate the importance of peer reviewed publication, ${ }^{43}{ }^{44}$ but our data show that ClinicalTrials.gov can serve a useful role in enhancing the completeness of available information. ${ }^{12}$

Some considerations on the search for published reports are needed. A previous surve ${ }^{20}$ found that a substantial proportion of randomized controlled trials (40-45\%) is still being published without the reporting of a trial registration code, thereby weakening the ability of the researchers to identify multiple publications of the same trial, cross check the published report with the original design, and investigate selective reporting. ${ }^{34}$ Another study found that $16 / 35(46 \%)$ vaccine trials, published in 2006-11, did not report the registration code. ${ }^{9}$ In our analysis we "easily" retrieved (by just typing the trial registration code in Scopus or PubMed or following a direct link from the ClinicalTrials.gov registry page) 132 of the 176 published reports. To find the other 44 publications we had to perform more challenging searches, using multiple combinations of title words and trial characteristics, for each of the remaining 223 completed trials. Notably, of the 44,17 simply did not report the registration code (despite journal guidelines), whereas 27 did report the registration code but this was not indexed. In most cases, this was probably due to the inclusion of the registration code outside the formal text of the paper (that is, in the acknowledgments section). We thus not only support a stricter adherence to the 23rd item of the CONSORT checklist (reporting trial registry name and number ${ }^{45}$ ), but we also suggest that this should be reported in the abstract to avoid missing indexing.

\section{Strengths and limitations of this study}

Some limitations should be acknowledged. Firstly, we may have missed some published reports. However, as discussed, given the efforts to identify publications, any missed papers are unlikely to be identified during routine or even systematic searches. ${ }^{10}$ Secondly, it is possible that some additional trials were not registered. The publication rate of unregistered vaccine trials, if they exist, is unknown, but such trials are likely to be less influential in the current environment where registration is widely accepted. One study found that $39 \%$ of randomized controlled trials published in a Medline sample were not registered in ClinicalTrials.gov. ${ }^{20}$ Thirdly, registry information including sample size and time of completion are inconsistently updated. ${ }^{576}$ We did use some form of adjustment for the date of completion, and the estimates on both sample size and time to completion of unpublished studies must be considered an approximation. However, when we repeated multivariable analyses excluding the trials without a completion or starting date $(n=14)$, the results were similar. Fourthly, even when data are reported in registry entries, these may not be accurate, and primary outcomes or sample size might differ between registry entries (in their various versions) and published reports. ${ }^{47}$ However, we examined the history of changes of the registry entries of a random sample of $30 \%$ of the 176 published trials $(n=53)$ : compared with registry entry, we found a substantially different sample size $(>10 \%$ or $\leq 10 \%)$ in seven published trials, and only one trial reported a different primary outcome. Such a small rate of variation in the primary outcome could be explained by the relatively high standardization of efficacy or immunogenicity outcomes in the vaccine discipline.

Finally, 75 trials in our sample (19\%) were registered after the study start ( $\mathrm{n}=49$ within three months), which may have introduced some bias. ${ }^{6}$ However, we repeated all analyses excluding such trials with similar results (details available from the authors).

\section{Conclusions}

The amount of randomized evidence on vaccines that remains unpublished may be lower than that of other medical specialties, but several trials had no results published or posted for many years after their completion. Actions are required to ensure timely public dissemination of trial data in published reports that can be easily linked to the trial registration codes. Given that the findings of vaccine trials may require an even prompter dissemination than other drug trials, a different publication model-including posting the main results on trial registries immediately and even before journal peer review—may be reasonable and encouraged. Also, since the approval process for vaccines and other drugs differ, the publication of findings could be linked more closely to the regulatory review.

Contributors: All authors participated in the design, analysis, and interpretation of the study. LM, PV, and JPAI were involved in all phases of the study. JPAI and LM led the statistical analysis and assisted MD, LC, MEF, and CD in data extraction. MD, MEF, and CD carried out the methodological quality assessment. LM, MEF, and JPAI wrote the manuscript. LM is the guarantor for all data.

Funding: This study was not funded.

Competing interests: All authors have completed the ICMJE uniform disclosure form at www.icmje.org/coi_disclosure.pdf and declare: no support from any organization for the submitted work; no financial relationships with any organization that might have an interest in the submitted work in the previous three years; no other relationships or activities that could appear to have influenced the submitted work.

\section{Ethical approval: Not required.}

Data sharing: No additional data.

Transparency: The guarantor affirms that the manuscript is a honest, accurate, and transparent account of the study being reported; that no important aspects of the study have been omitted; and that any discrepancies from the study as planned (and, if relevant, registered) have been explained.

1 Sibbald B, Roland M. Understanding controlled trials. Why are randomised controlled trials important? BMJ 1998;316:201.

2 Manzoli L, De Vito C, Salanti G, D'Addario M, Villari P, loannidis JP. Meta-analysis of the immunogenicity and tolerability of pandemic influenza A 2009 (H1N1) vaccines. PLoS One 2011;6:e24384.

3 Leung GM, Nicoll A. Reflections on pandemic (H1N1) 2009 and the international response. PLOS Med 2010;7.

4 loannidis JP, Lau J. Completeness of safety reporting in randomized trials: an evaluation of 7 medical areas. JAMA 2001;285:437-43.

5 Chan AW, Song F, Vickers A, Jefferson T, Dickersin K, Gotzsche PC, et al. Increasing value and reducing waste: addressing inaccessible research. Lancet 2014;383:257-66.

6 Dwan K, Altman DG, Arnaiz JA, Bloom J, Chan AW, Cronin E, et al. Systematic review of the empirical evidence of study publication bias and outcome reporting bias. PLOS One 2008;3:e3081.

7 Wu J, Li W, Wang HQ, Chen JT, Lv M, Zhou JC, et al. A rapid immune response to 2009 influenza $\mathrm{A}(\mathrm{H} 1 \mathrm{~N} 1)$ vaccines in adults: a randomized, double-blind, controlled trial. $J$ Infect influenza $A(\mathrm{H} 1 \mathrm{~N} 1)$ vaccin
Dis 2010;202:675-80.

8 loannidis JP, Manzoli L, De Vito C, D'Addario M, Villari P. Publication delay of randomized trials on 2009 influenza A (H1N1) vaccination. PLoS One 2011;6:e28346.

9 Scott $\mathrm{P}, \mathrm{Ott} F$, Egger M, Low N. Completeness of reporting in randomized controlled trials of 3 vaccines: a review of adherence to the CONSORT checklist. Pediatr Infect Dis $J$ 2012;31:1286-94.

10 Jones CW, Handler L, Crowell KE, Keil LG, Weaver MA, Platts-Mills TF. Non-publication of large randomized clinical trials: cross sectional analysis. BMJ 2013;347:f6104.

11 Verstraeten T, Descamps D, David MP, Zahaf T, Hardt K, Izurieta P, et al. Analysis of adverse events of potential autoimmune aetiology in a large integrated safety database of AS04 adjuvanted vaccines. Vaccine 2008;26:6630-8.

12 Riveros C, Dechartres A, Perrodeau E, Haneef R, Boutron I, Ravaud P. Timing and completeness of trial results posted at ClinicalTrials.gov and published in journals. PLOS Med 2013;10:e1001566; discussion e66.

13 Galsworthy MJ, Hristovski D, Lusa L, Ernst K, Irwin R, Charlesworth K, et al. Academic output of 9 years of EU investment into health research. Lancet 2012;380:971-2.

14 Gordon D, Taddei-Peters W, Mascette A, Antman M, Kaufmann PG, Lauer MS. Publication of trials funded by the National Heart, Lung, and Blood Institute. N Engl J Med 2013;369:1926-34. 


\section{What is already known on this topic}

For epidemic diseases, delayed or non-publication of randomized trials results may distort the available evidence that is used for recommendations, resource allocation, drug/vaccine stockpiling, and other public actions

A growing body of evidence indicates that a significant proportion of randomized controlled trial (RCT) results remains unpublished, or get published with major delay; only two studies focused on vaccines

A first analysis did not assess delay to publication; in the other study, the publication was evaluated for delay of RCTs on a single vaccine after a relatively short time from the onset of a pandemic (two years)

\section{What this study adds}

Most vaccine trials get published eventually or have results posted in ClinicalTrials.gov, but delays of several years to publication are common

The publication to delay between non-industry and industry sponsored trials did not differ, but trials not sponsored by industry were more likely to report negative findings

15 Krzyzanowska MK, Pintilie M, Tannock IF. Factors associated with failure to publish large randomized trials presented at an oncology meeting. JAMA 2003;290:495-501.

16 Lee K, Bacchetti P, Sim I. Publication of clinical trials supporting successful new drug applications: a literature analysis. PLOS Med 2008:5:e191.

17 Rising K, Bacchetti P, Bero L. Reporting bias in drug trials submitted to the Food and Drug Administration: review of publication and presentation. PLOS Med 2008;5:e217; discussion e17.

18 Turner EH, Knoepflmacher D, Shapley L. Publication bias in antipsychotic trials: an analysis of efficacy comparing the published literature to the US Food and Drug Administration database. PLoS Med 2012;9:e1001189.

19 Turner EH, Matthews AM, Linardatos E, Tell RA, Rosenthal R. Selective publication of antidepressant trials and its influence on apparent efficacy. N Engl J Med 2008;358:252-60.

20 Van de Wetering FT, Scholten RJ, Haring T, Clarke M, Hooft L. Trial registration numbers are underreported in biomedical publications. PLoS One 2012;7:e49599.

21 Dickersin K, Min YI. NIH clinical trials and publication bias. Online J Curr Clin Trials 1993;Doc No 50.

22 Turner S, Wright D, Maeso R, Cook A, Milne R. Publication rate for funded studies from a major UK health research funder: a cohort study. BMJ Open 2013;3(5).

23 Dickersin K, Min Yl, Meinert CL. Factors influencing publication of research results. Follow-up of applications submitted to two institutional review boards. JAMA 1992;267:374-8.

24 Patsopoulos NA, loannidis JP. The use of older studies in meta-analyses of medical interventions: a survey. Open Med 2009;3:e62-8.

25 World Medical Association. Declaration of Helsinki: ethical principles for medical research involving human subjects. Fortaleza, Brasil: 64th WMA General Assembly, 2013.

26 Strech D. Normative arguments and new solutions for the unbiased registration and publication of clinical trials. J Clin Epidemiol 2012;65:276-81.

27 Chalmers I. Underreporting research is scientific misconduct. JAMA 1990;263:1405-8.

28 Federal Policy for the Protection of Human Subjects: Code of Federal Regulations (CFR), 2009.

29 Ross JS, Tse T, Zarin DA, Xu H, Zhou L, Krumholz HM. Publication of NIH funded trials registered in ClinicalTrials. gov: cross sectional analysis. BMJ 2012;344:d7292.

30 Macleod MR, Michie S, Roberts I, Dirnagl U, Chalmers I, loannidis JP, et al. Biomedical research: increasing value, reducing waste. Lancet 2014;383:101-4.

31 Manzoli L, Salanti G, De Vito C, Boccia A, loannidis JP, Villari P. Immunogenicity and adverse events of avian influenza A H5N1 vaccine in healthy adults: multiple-treatments meta-analysis. Lancet Infect Dis 2009;9:482-92.

32 Hopewell S, Loudon K, Clarke MJ, Oxman AD, Dickersin K. Publication bias in clinical trials due to statistical significance or direction of trial results. Cochrane Database Syst Rev 2009;1:MR000006.

33 Stern JM, Simes RJ. Publication bias: evidence of delayed publication in a cohort study of clinical research projects. BMJ 1997;315:640-5.
34 Chan AW, Krleza-Jeric K, Schmid I, Altman DG. Outcome reporting bias in randomized trials funded by the Canadian Institutes of Health Research. CMAJ 2004;171:735-40.

35 Decullier $E$, Chapuis $F$. Impact of funding on biomedical research: a retrospective cohort study. BMC Public Health 2006:6:165.

36 Decullier $E$, Lheritier V, Chapuis $F$. Fate of biomedical research protocols and publication bias in France: retrospective cohort study. BMJ 2005;331:19.

37 Ioannidis JP. Effect of the statistical significance of results on the time to completion and publication of randomized efficacy trials. JAMA 1998;279:281-6.

38 Easterbrook PJ, Berlin JA, Gopalan R, Matthews DR. Publication bias in clinical research. Lancet 1991;337:867-72.

39 Ross JS, Mulvey GK, Hines EM, Nissen SE, Krumholz HM. Trial publication after registration in ClinicalTrials.Gov: a cross-sectional analysis. PLoS Med 2009;6:e1000144.

40 Von Elm E, Rollin A, Blumle A, Huwiler K, Witschi M, Egger M. Publication and non-publication of clinical trials: Iongitudinal study of applications submitted to a research ethics committee. Swiss Med Wkly 2008;138:197-203.

41 Shamliyan T, Kane RL. Clinical research involving children: registration, completeness, and publication. Pediatrics 2012;129:e1291-300.

42 Young NS, loannidis JP, Al-Ubaydli O. Why current publication practices may distort science. PLOS Med 2008;5:e201.

43 Goodman SN, Berlin J, Fletcher SW, Fletcher RH. Manuscript quality before and after peer review and editing at Annals of Internal Medicine. Ann Intern Med 1994;121:11-21.

44 Cobo E, Selva-O'Callagham A, Ribera JM, Cardellach F, Dominguez R, Vilardell M. Statistical reviewers improve reporting in biomedical articles: a randomized trial. PLOS One 2007;2:e332.

45 Schulz KF, Altman DG, Moher D. CONSORT 2010 statement: updated guidelines for reporting parallel group randomised trials. BMJ 2010;340:c332.

46 Bourgeois FT, Murthy S, Mandl KD. Outcome reporting among drug trials registered in ClinicalTrials.gov. Ann Intern Med 2010;153:158-66.

47 Vedula SS, Bero L, Scherer RW, Dickersin K. Outcome reporting in industry-sponsored trials of gabapentin for off-label use. N Engl J Med 2009;361:1963-71.

\section{Accepted: 24 April 2014}

\section{Cite this as: BMJ 2014;348:g3058}

This is an Open Access article distributed in accordance with the Creative Commons Attribution Non Commercial (CC BY-NC 3.0) license, which permits others to distribute, remix, adapt, build upon this work non-commercially, and license their derivative works on different terms, provided the original work is properly cited and the use is non-commercial. See: http://creativecommons.org/licenses/by-nc/3.0/. 


\section{Tables}

\begin{tabular}{|c|c|c|c|c|c|c|}
\hline Variables & Overall & H1N1 & HPV & Meningococcal & Pneumococcal & Rotavirus \\
\hline \multicolumn{7}{|l|}{ Starting year (No RCTs, \%): } \\
\hline 2006 & $63(16.4)$ & - & $12(20.0)$ & $24(20.5)$ & $18(21.7)$ & $9(22.0)$ \\
\hline 2007 & $61(15.9)$ & - & $17(28.3)$ & $25(21.4)$ & $15(18.1)$ & $4(9.8)$ \\
\hline 2008 & $38(9.9)$ & - & $9(15.0)$ & $17(14.5)$ & $9(10.8)$ & $3(7.3)$ \\
\hline 2009 & $97(25.3)$ & $61(73.5)$ & $6(10.0)$ & $13(11.1)$ & $11(13.3)$ & $6(14.6)$ \\
\hline 2010 & $56(14.6)$ & $21(25.3)$ & $3(5.0)$ & $12(10.3)$ & $11(13.3)$ & $9(22.0)$ \\
\hline 2011 & $37(9.6)$ & $0(0.0)$ & $8(13.3)$ & $15(12.8)$ & $9(10.8)$ & $5(12.2)$ \\
\hline 2012 & $32(8.3)$ & $1(1.2)$ & $5(8.3)$ & $11(9.4)$ & $10(12.0)$ & $5(12.2)$ \\
\hline Overall No RCTs (total sample) & $384(607076)$ & $83(52483)$ & $60(228$ 117) & $117(118813)$ & 83 (155 952) & $41(51711)$ \\
\hline \multicolumn{7}{|l|}{ Completed: } \\
\hline No of registered RCTs (sample) & $355(404758)$ & $83(52483)$ & $52(62536)$ & $108(105725)$ & $77(150811)$ & 35 (33 203) \\
\hline $\begin{array}{l}\% \text { of registered RCTs (\% of } \\
\text { sample) }\end{array}$ & $92.5(66.7)$ & $100(100)$ & $86.7(27.4)$ & $92.3(89.0)$ & $92.8(96.7)$ & $85.4(64.2)$ \\
\hline \multicolumn{7}{|l|}{$\begin{array}{l}\text { Published in peer reviewed } \\
\text { journals: }\end{array}$} \\
\hline No of completed RCTs (sample) & 176 (151 379) & $53(28072)$ & $23(19659)$ & $47(58580)$ & $38(25$ 547) & $15(19521)$ \\
\hline $\begin{array}{l}\% \text { of completed RCTs (\% of } \\
\text { sample) }\end{array}$ & $49.6(37.4)$ & $63.9(53.5)$ & $44.2(31.4)$ & $43.5(55.4)$ & $49.3(16.9)$ & $42.9(58.8)$ \\
\hline \multicolumn{7}{|l|}{$\begin{array}{l}\text { Unpublished but results in } \\
\text { ClinicalTrials.gov }\end{array}$} \\
\hline No of completed RCTs (sample) & $42(62765)$ & 7 (5915) & $9(10496)$ & $11(15$ 101) & $11(29875)$ & $4(1378)$ \\
\hline $\begin{array}{l}\% \text { of completed RCTs (\% of } \\
\text { sample) }\end{array}$ & $11.8(15.5)$ & $8.4(11.3)$ & $17.3(16.8)$ & $10.2(14.3)$ & $14.3(19.8)$ & $11.4(4.2)$ \\
\hline $\begin{array}{l}\text { Median (interquartile range) time } \\
\text { from start to completion (months) }\end{array}$ & $15.2(17.2)$ & $7.1(11.2)$ & $17.8(18.8)$ & $17.2(13.2)$ & $16.3(14.3)$ & $15.2(18.3)$ \\
\hline $\begin{array}{l}\text { Median (interquartile range) time } \\
\text { from completion to publication } \\
\text { (months) }\end{array}$ & $26.4(27.5)$ & $22.4(22.3)$ & $23.9(26.3)$ & $29.4(32.5)$ & $28.4(25.4)$ & $28.5(36.6)$ \\
\hline \multicolumn{7}{|l|}{$\begin{array}{l}\% \text { of RCTs (\% of sample) } \\
\text { published: }\end{array}$} \\
\hline 12 months after completion $\dagger$ & $11.9(9.3)$ & $27.7(20.1)$ & $8.3(19.5)$ & $5.9(2.2)$ & $5.6(4.3)$ & $9.1(10.9)$ \\
\hline 24 months after completion $\ddagger$ & $28.8(28.2)$ & $52.0(40.3)$ & $26.8(35.8)$ & $18.6(19.0)$ & $18.3(16.6)$ & $23.3(50.2)$ \\
\hline 36 months after completion§ & $53.1(59.1)$ & $74.6(71.8)$ & $50.0(59.3)$ & $41.9(53.3)$ & $46.3(49.9)$ & $44.4(67.2)$ \\
\hline 48 months after completion $\mathbb{1}$ & $73.0(80.6)$ & $85.5(79.2)$ & $71.0(82.3)$ & $61.4(80.6)$ & $74.0(83.5)$ & $75.0(77.7)$ \\
\hline \multicolumn{7}{|l|}{$\begin{array}{l}\text { Registration pattern (No (\%) } \\
\text { RCTs): }\end{array}$} \\
\hline Registered before start date & $311(81.0)$ & $65(78.3)$ & $52(86.7)$ & $95(81.2)$ & $67(80.7)$ & $32(78.0)$ \\
\hline $\begin{array}{l}\text { Registered } \leq 3 \text { months after start } \\
\text { date }\end{array}$ & $49(12.8)$ & $13(15.7)$ & $6(10.0)$ & $17(14.4)$ & $11(13.3)$ & $2(4.9)$ \\
\hline $\begin{array}{l}\text { Registered }>3 \text { months after start } \\
\text { date }\end{array}$ & $24(6.2)$ & $5(6.0)$ & $2(3.3)$ & $5(4.3)$ & $5(6.0)$ & $7(17.1)$ \\
\hline \multicolumn{7}{|l|}{ Trial registry (No (\%) of RCTs): } \\
\hline $\begin{array}{l}\text { Registered (also) in } \\
\text { ClinicalTrials.gov }\end{array}$ & $347(90.4)$ & $72(86.7)$ & $57(95.0)$ & $109(93.2)$ & $76(91.6)$ & $33(80.5)$ \\
\hline $\begin{array}{l}\text { Registered (only) in other } \\
\text { registries }\end{array}$ & $37(9.6)$ & $11(13.3)$ & $3(5.0)$ & $8(6.8)$ & $7(8.4)$ & $8(19.5)$ \\
\hline $\begin{array}{l}\text { Trial registry No reported in } \\
\text { published reports (No, \%) }\end{array}$ & $159(90.3)$ & $49(92.4)$ & $16(69.6)$ & $44(93.6)$ & $35(92.1)$ & $15(100)$ \\
\hline $\begin{array}{l}\text { Published report easily retrievable } \\
\text { through trial registry No (No, \%) }\end{array}$ & $132(75.0)$ & $36(67.9)$ & $16(69.6)$ & $39(83.0)$ & $30(78.9)$ & $11(73.3)$ \\
\hline
\end{tabular}


Table 1 (continued)

\begin{tabular}{|c|c|c|c|c|c|c|}
\hline Variables & Overall & H1N1 & HPV & Meningococcal & Pneumococcal & Rotavirus \\
\hline 1 & $41(10.7)$ & $9(10.8)$ & $6(10.0)$ & $5(4.3)$ & $12(14.5)$ & $9(22.0)$ \\
\hline 2 & $103(26.8)$ & $35(42.2)$ & $11(18.3)$ & $36(30.8)$ & $12(14.5)$ & $9(22.0)$ \\
\hline 3 & $192(50.0)$ & $27(32.5)$ & $34(56.7)$ & $67(57.3)$ & $49(59.0)$ & $15(36.6)$ \\
\hline 4 & $34(8.9)$ & $8(9.6)$ & $5(8.3)$ & $8(6.8)$ & $6(7.2)$ & $7(17.1)$ \\
\hline Unknown & $14(3.6)$ & $4(4.8)$ & $4(6.7)$ & $1(0.9)$ & $4(4.8)$ & $1(2.4)$ \\
\hline \multicolumn{7}{|l|}{ Age range (No (\%) of RCTs): } \\
\hline Children (years) & $227(59.1)$ & $27(32.5)$ & $21(35.0)$ & $87(74.4)$ & $60(72.3)$ & $32(78.0)$ \\
\hline Adults & $85(22.1)$ & $28(33.7)$ & $28(46.7)$ & $14(12.0)$ & $10(12.0)$ & $5(12.2)$ \\
\hline Elderly & $14(3.6)$ & $4(4.8)$ & $0(0.0)$ & $1(0.9)$ & $8(9.6)$ & $1(2.4)$ \\
\hline Mixed ages & $58(15.1)$ & $24(28.9)$ & $11(18.3)$ & $15(12.8)$ & $5(6.0)$ & $3(7.3)$ \\
\hline \multicolumn{7}{|l|}{$\begin{array}{l}\text { Sponsor (No of RCTs (total } \\
\text { sample): }\end{array}$} \\
\hline Non-profit & $58(59141)$ & 20 (8985) & $6(22$ 259) & $7(2444)$ & $11(5163)$ & $14(20290)$ \\
\hline GlaxoSmithKline & $140(276$ 202) & $20(15248)$ & $32(166563)$ & $39(38453)$ & $35(41692)$ & $14(14246)$ \\
\hline Novartis & $46(57715)$ & $11(9014)$ & $1(801)$ & $34(47900)$ & $0(0)$ & $0(0)$ \\
\hline Pfizer/Wyeth & $39(119070)$ & $0(0)$ & $1(2500)$ & $11(12055)$ & 27 (104 515) & $0(0)$ \\
\hline Merck & $25(40077)$ & $0(0)$ & $15(27610)$ & $1(1042)$ & $3(1994)$ & $6(9431)$ \\
\hline Sanofi-Aventis & $26(13190)$ & $7(3227)$ & $1(600)$ & $13(6849)$ & $5(2514)$ & $0(0)$ \\
\hline Other companies & $50(41681)$ & $25(16009)$ & $4(7784)$ & $12\left(\begin{array}{lll}10 & 070\end{array}\right)$ & $2(74)$ & $7(7744)$ \\
\hline $\begin{array}{l}\text { Median (interquartile range) } 2011 \\
\text { impact factor }\end{array}$ & $3.78(0.19)$ & $3.78(2.83)$ & $3.58(0.83)$ & $3.58(0.19)$ & $3.58(0.19)$ & $3.78(2.83)$ \\
\hline \multicolumn{7}{|l|}{ Journals publishing trials (No, \%): } \\
\hline Vaccine & $52(29.6)$ & $21(39.6)$ & $7(30.4)$ & $8(17.0)$ & $10(26.3)$ & $6(40.0)$ \\
\hline $\begin{array}{l}\text { Pediatric Infectious Disease } \\
\text { Journal }\end{array}$ & $33(18.8)$ & $2(3.8)$ & $2(8.7)$ & $13(27.7)$ & $16(42.1)$ & 0() \\
\hline $\begin{array}{l}\text { Human Vaccines and } \\
\text { Immunotherapeutics }\end{array}$ & $20(11.4)$ & $6(11.3)$ & $3(13.0)$ & $6(12.8)$ & $1(2.6)$ & $4(26.7)$ \\
\hline $\begin{array}{l}\text { Lancet, BMJ, JAMA, or New } \\
\text { England Journal of Medicine }\end{array}$ & $18(10.2)$ & $7(13.2)$ & $2(8.7)$ & $6(12.8)$ & $2(5.3)$ & $1(6.7)$ \\
\hline Others & $53(30.1)$ & $17(32.1)$ & $9(39.1)$ & $14(29.8)$ & $9(23.7)$ & $4(26.7)$ \\
\hline \multicolumn{7}{|l|}{ Published trial results (No, \%): } \\
\hline Positive & $158(89.8)$ & $44(83.0)$ & $21(91.3)$ & $43(91.5)$ & $36(94.7)$ & $14(93.3)$ \\
\hline Mixed & $14(7.9)$ & $6(11.3)$ & $2(8.7)$ & $4(8.5)$ & $1(2.6)$ & $1(6.7)$ \\
\hline Mostly negative & $4(2.3)$ & $3(5.7)$ & $0(0.0)$ & $0(0.0)$ & $1(2.6)$ & $0(0.0)$ \\
\hline
\end{tabular}

H1N1= pandemic A/H1N1 2009 influenza; HPV=human papillomavirus.

*Unpublished trials censored at 1 February 2014.

†Only trials that were completed from $\geq 12$ months (or published before) were included in this analysis ( $n=337$ overall; $n=83$ trials on $H 1 N 1$ vaccine; $n=48$ on HPV vaccine; $n=101$ on meningococcal vaccine; $n=72$ on pneumococcal vaccine; $n=33$ on rotavirus vaccine).

$\ddagger$ Only trials completed from $\geq 24$ months (or published before) were included in this analysis ( $n=292 ; n=75 ; n=41 ; n=86 ; n=60 ; n=30$ ). §Only trials completed from $\geq 36$ months (or published before) were included in this analysis ( $n=260 ; n=71 ; n=34 ; n=74 ; n=54 ; n=27$ ). TOnly trials completed from $\geq 48$ months (or published before) were included in this analysis ( $n=233 ; n=62 ; n=31 ; n=70 ; n=50 ; n=20$ ). ${ }^{* *}$ Trial phase was assigned based on what was reported in registry entries. If not available $(n=4)$, phase was assigned by authors. 


\begin{tabular}{|c|c|c|c|c|c|c|c|c|}
\hline \multirow[b]{2}{*}{ Sponsor } & \multirow[b]{2}{*}{ Overall } & \multirow[b]{2}{*}{ Completed } & \multirow{2}{*}{$\begin{array}{l}\text { Completed } \\
\text { and } \\
\text { published }\end{array}$} & \multirow[b]{2}{*}{$\begin{array}{l}\text { Completed } \\
\text { with results }\end{array}$} & \multicolumn{3}{|c|}{ Median (interquartile range) time (months) } & \multirow{2}{*}{$\begin{array}{c}\%(\mathrm{No}) \text { of } \\
\text { trials with } \\
\text { positive } \\
\text { results }\end{array}$} \\
\hline & & & & & $\begin{array}{c}\text { Start to } \\
\text { completion }\end{array}$ & $\begin{array}{l}\text { Completion to } \\
\text { publication } \dagger\end{array}$ & $\begin{array}{c}\text { Start to } \\
\text { publication } \dagger\end{array}$ & \\
\hline $\begin{array}{l}\text { Non-profit institution } \\
\text { (No of trials, No in } \\
\text { sample) }\end{array}$ & $58(59141)$ & $46(25$ 203) & $22(10702)$ & $24(12090)$ & $10.6(18.3)$ & $25.4(21.4)$ & $40.6(20.4)$ & $68.2(7)$ \\
\hline $\begin{array}{l}\text { All industry(No of } \\
\text { trials, No in sample) }\end{array}$ & $326(547$ 935) & 309 (379 555) & $154(140.677)$ & $194(202$ 054) & $14.2(16.2)$ & $28.5(27.4)$ & $46.7(25.4)$ & $92.9(11)$ \\
\hline Single companies: & & $\%(n)$ & $\%(n)$ & $\%(n)$ & & & & \\
\hline GlaxoSmithKline & $140(276202)$ & $94.3(132)$ & $61.4(81)$ & $72.0(95)$ & $13.2(13.8)$ & $29.5(28.0)$ & $47.2(24.9)$ & $95.1(4)$ \\
\hline Novartis & $46(57715)$ & $97.8(45)$ & $40.0(18)$ & $53.3(24)$ & $13.7(18.3)$ & $27.4(23.4)$ & $42.1(25.4)$ & $83.3(3)$ \\
\hline Pfizer/Wyeth & $39(119070)$ & $92.3(36)$ & $52.8(19)$ & $75.0(27)$ & $19.3(9.2)$ & $34.5(26.5)$ & $56.8(35.5)$ & $94.7(1)$ \\
\hline Merck & $25(40077)$ & $100.0(25)$ & $24.0(6)$ & $44.0(11)$ & $19.3(10.2)$ & $36.5(25.4)$ & $53.8(32.5)$ & $100.0(0)$ \\
\hline Sanofi-Aventis & $26(13$ 190) & $92.3(24)$ & $45.8(11)$ & $70.8(17)$ & $14.2(12.2)$ & $20.8(29.3)$ & $34.5(44.5)$ & $100.0(0)$ \\
\hline Other companies & $50(41681)$ & $94.0(47)$ & $40.4(19)$ & $42.5(20)$ & $11.2(20.3)$ & $19.8(21.2)$ & $35.6(26.3)$ & $84.2(3)$ \\
\hline
\end{tabular}

*Including trials with results not published in peer reviewed journals but reported in ClinicalTrials.gov. †Unpublished trials censored at 1 February 2014. 
Table 3| Potential predictors of time to publication

\begin{tabular}{|c|c|c|c|}
\hline \multirow[t]{2}{*}{ Predictors } & \multicolumn{3}{|c|}{ Hazard ratio $(95 \% \mathrm{Cl})$} \\
\hline & Completion to publication & Start to completion & Start to publication \\
\hline Sample size (logarithm) & 1.14 (0.99 to 1.31$)$ & 0.79 (0.73 to 0.86$)$ & 0.89 (0.78 to 1.03$)$ \\
\hline \multicolumn{4}{|l|}{ Vaccine (general): } \\
\hline All other $v \mathrm{H} 1 \mathrm{~N} 1$ & $0.37(0.24$ to 0.57$)$ & $0.34(0.25$ to 0.46$)$ & $0.24(0.15$ to 0.36$)$ \\
\hline \multicolumn{4}{|l|}{ Vaccine (detailed): } \\
\hline H1N1 (ref category) & 1 & 1 & 1 \\
\hline $\mathrm{HPV}$ & $0.45(0.25$ to 0.81$)$ & 0.26 (0.17 to 0.40$)$ & 0.22 (0.12 to 0.41$)$ \\
\hline Meningococcal & $0.33(0.20$ to 0.53$)$ & 0.28 (0.19 to 0.40$)$ & $0.20(0.12$ to 0.33$)$ \\
\hline Pneumococcal & 0.41 (0.24 to 0.71$)$ & 0.43 (0.29 to 0.62 ) & 0.28 (0.16 to 0.48$)$ \\
\hline Rotavirus & $0.39(0.21$ to 0.74$)$ & 0.47 (0.31 to 0.71$)$ & $0.30(0.16$ to 0.57$)$ \\
\hline \multicolumn{4}{|l|}{ Sponsor (general) } \\
\hline Industry $v$ non-profit & 1.05 (0.66 to 1.69$)$ & 1.45 (1.04 to 2.00$)$ & $1.11(0.70$ to 1.75$)$ \\
\hline \multicolumn{4}{|l|}{ Sponsor (detailed): } \\
\hline Non-profit (ref category) & 1 & 1 & 1 \\
\hline GlaxoSmithKline & $1.30(0.78$ to 2.16$)$ & 1.60 (1.11 to 2.31$)$ & 1.38 (0.84 to 2.28$)$ \\
\hline Novartis & 0.79 (0.41 to 1.51$)$ & 3.13 (1.91 to 5.13 ) & 1.05 (0.55 to 2.03$)$ \\
\hline Pfizer/Wyeth & 0.97 (0.46 to 2.02$)$ & 1.29 (0.79 to 3.15$)$ & $0.90(0.44$ to 1.86$)$ \\
\hline Merck & $0.44(0.17$ to 1.14$)$ & 1.82 (1.05 to 3.15$)$ & $0.47(0.18$ to 1.23$)$ \\
\hline Sanofi-Aventis & $1.16(0.55$ to 2.47$)$ & 1.76 (1.04 to 2.96$)$ & $1.18(0.56$ to 2.50$)$ \\
\hline Other companies & $1.12(0.60$ to 2.07$)$ & $1.12(0.73$ to 1.71$)$ & $0.97(0.52$ to 1.80$)$ \\
\hline
\end{tabular}

H1N1= pandemic A/H1N1 2009 influenza; HPV=human papillomavirus. 


\section{Figure}

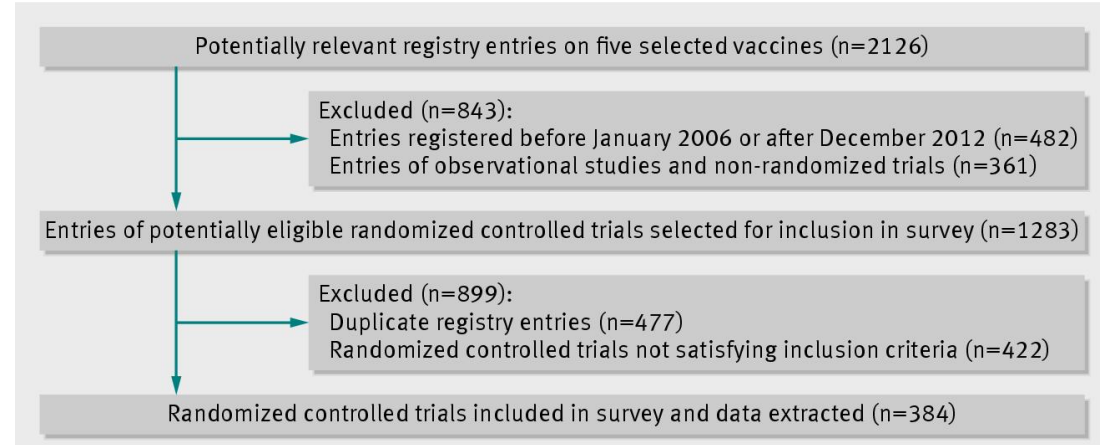

Flow diagram of trial selection process 